\title{
CYCLIC TESTING OF UNBONDED POST-TENSIONED CONCRETE WALL SYSTEMS WITH AND WITHOUT SUPPLEMENTAL DAMPING
}

\author{
K M Twigden ${ }^{\mathrm{a}}$, S Sritharan ${ }^{\mathrm{b}}$, and R S Henry ${ }^{\mathrm{a}}$
}

\begin{abstract}
A series of cyclic lateral-load tests were conducted on four different unbonded post-tensioned precast concrete wall systems, including two Single Rocking Walls (SRW) and two PREcast Wall with End Columns (PreWEC). The main purpose of these tests was to systematically investigate the cyclic response of post-tensioned concrete walls with varying amounts of supplemental damping while keeping the initial post-tensioning force, wall dimensions, and confinement details constant. A secondary objective was to validate the wall panel design including the appropriate selection of axial force ratio and design of confinement and armouring details. All of the test walls exhibited excellent performance with uplift and rocking at the wall base with only minor damage observed, consisting of small amounts of spalling in the wall toes. There were consistent observations and measurements of the wall damage, concrete compressive strains, and wall neutral axis depths for both the SRW and PreWEC systems with the same wall panel dimensions. Based on these observations it is concluded that the behaviour of the wall panel in a PreWEC system is independent of the number of energy dissipating O-connectors. The O-connectors increased the hysteretic energy dissipation in the wall system and provided between 1.1-1.4\% of additional equivalent viscous damping per connector for the PreWEC walls tested. Overall, the behaviour of the four walls tested confirmed the design procedures used, with both the global force-displacement response and local response parameters predicted with sufficient accuracy using an existing simplified analysis method.
\end{abstract}

Keywords: Self-centering; Unbonded Post-Tensioning; Precast Concrete; Shear Walls; Cyclic Testing; PreWEC; OConnector 


\section{$1 \quad 1 \quad$ INTRODUCTION}

2 Structural concrete walls provide strong, stiff, lateral-load resisting elements that can reduce lateral drifts during

3 earthquakes. However, the plastic hinge regions in ductile reinforced concrete walls are subjected to large inelastic strain

4 demands during earthquakes that result in significant structural damage. Recent earthquakes have highlighted the impact

5 of damage caused to ductile reinforced concrete structures, which can result in large economic costs due to business

6 down time, repairs, demolition, and rebuilding $[1,2]$. In an effort to control the damage in a structure to a certain

7 performance level and isolate irreparable damage to easily replaceable components, engineers and researchers have

8 developed low-damage seismic resisting systems. Low-damage seismic resisting wall systems can be designed using

9 unbonded post-tensioned (PT) precast concrete panels. Inelastic demand in unbonded PT walls is accommodated through

10 the opening and closing of an existing joint at the wall base, introducing a rocking mechanism. In addition to providing

11 lateral strength to the wall, the unbonded PT tendons are designed to remain elastic during a design-level earthquake to

12 provide a restoring force to minimise residual drifts.

13 The concept of connecting precast concrete elements together with unbonded PT was introduced during the PREcast

14 Seismic Structural Systems (PRESSS) research program conducted in the 1990's [3]. During the PRESSS program a

15 jointed wall system was developed that consists of two or more PT precast concrete panels connected by energy

16 dissipating connectors. The jointed wall system was included in a five storey prototype building that was tested by

17 Priestley et al. [3]. Following introduction of the PT wall concept, several researchers have investigated simple PT wall

18 systems that consist of a single precast concrete panel with no additional energy dissipating connectors [4-6]. These PT

19 only wall systems uplift and rock at the wall base with no significant material inelasticity and therefore result in low

20 energy dissipation during cyclic loading. To improve the energy dissipation ability or seismic performance of the

21 unbonded PT concrete walls, additional energy dissipating elements are often used. Researchers have investigated several

22 configurations of unbonded PT concrete wall systems with different energy dissipating elements, such as the previously

23 discussed jointed wall system. An alternative hybrid system was also developed that consists of a single precast concrete

24 wall with a combination of unbonded PT and mild steel reinforcement at the wall-to-foundation interface. A number of

25 researchers have experimentally investigated the hybrid system using either mild steel dissipaters [7-11] and/or viscous

26 dampers [12]. Analytical investigations into hybrid walls with viscous damping, friction damping and hysteretic damping

27 provided using mild steel have been reported [13-15]. A PT wall system that used precast hollowcore panels was also

28 developed and tested for applications in warehouse buildings [16, 17]. 
29 Recently a new rocking wall system that consists of a PREcast Wall with End Columns (PreWEC) was developed and 30 experimentally validated [18]. The PreWEC system is a variation on the original jointed wall system, and uses a single

31 precast concrete wall panel with two end columns that are each anchored to the foundation using unbonded PT. The wall

32 is joined to the end columns with specially designed energy dissipating O-connectors developed for the PreWEC system

33 [19]. As with other unbonded PT concrete wall systems, the wall and columns are designed to uplift and rock when a

34 lateral load is applied, with the floor diaphragms connecting the wall and end columns in the horizontal plane. The uplift

35 at the wall base results in a relative vertical displacement along the joint between the wall and end columns where the O-

36 connectors are attached. As a result of this vertical displacement, the O-connectors undergo flexural yielding and

37 dissipate seismic energy. The PreWEC system was developed to optimise the moment capacity of the jointed wall system

38 by maximising the lever arm between the PT tendons and the wall compression block. Another advantage of the system

39 is that the columns undergo relatively small uplift and can therefore be used to support the floor diaphragms and transfer

40 gravity loads. Wall-to-floor connection alternatives for the PreWEC system are discussed separately in Henry et al. [20]

41 and Sritharan et al. [18].

42 To better understand the behaviour of PreWEC walls, an experimental study of PT concrete wall systems was conducted.

43 A total of four wall systems were considered, including two single unbonded PT only walls, referred to as Single

44 Rocking Walls (SRW), and two PreWEC systems. The objective of these four wall tests was to systematically investigate

45 the cyclic response of walls with varying amounts of supplemental damping in the form of energy dissipating O-

46 connectors while keeping the initial post-tensioning, wall dimensions and confinement details constant. The wall tests

47 also provided an opportunity to further validate the wall panel design, including the choice of axial force ratio and

48 confinement details, and to compare the experimental results of the walls against an existing simplified analysis method

49 used for the design of PT wall systems.

\section{EXPERIMENTAL PROGRAM}

51 The experimental program consisted of pseudo-static cyclic testing of four walls, two SRWs and two PreWEC systems.

52 The specimen dimensions and parameters were selected to represent a target range of typical multi-storey commercial

53 buildings between two to eight stories high in a region with medium to high seismic hazard. The building typology

54 utilised unbonded PT precast concrete walls as the primary lateral force resisting system, and further details of the scale

55 and prototype building are published separately [21]. The design of the test walls followed the New Zealand Concrete

56 Structures Standard (NZS 3101:2006) [22] and used the design method for PT concrete walls proposed by Aaleti and

57 Sritharan [23]. The parameters of SRW-A and SRW-B were varied to investigate the behaviour of two different SRW 
systems with different geometry and initial post-tensioning force. PreWEC-A and PreWEC-B specimens were designed

59 based on the addition of end columns and energy dissipating O-connectors to SRW-B. To isolate the influence of the

60 number of O-connectors, all other parameters between SRW-B, PreWEC-A and PreWEC-B systems were kept constant.

61 Two cyclic tests were performed on PreWEC-A which are referred to as PreWEC-A1 and PreWEC-A2.

\section{$62 \quad 2.1 \quad$ Wall specifications}

63 The dimensions, design parameters, and cross section of each test wall are provided in Table 1 and Figure 1. SRW-A and

64 SRW-B consisted of a precast concrete wall panel cast with ducts along the length for placement of the unbonded PT

65 tendons. The wall panel used for SRW-A had a length, thickness and height of $1000 \mathrm{~mm}, 120 \mathrm{~mm}$ and $3000 \mathrm{~mm}$,

66 respectively, while the wall panel used for SRW-B had a length, thickness and height of $800 \mathrm{~mm}, 125 \mathrm{~mm}$ and $2860 \mathrm{~mm}$,

67 respectively. The PT tendons used for SRW-A were $15 \mathrm{~mm}$ diameter high strength bars and the PT tendons used for

68 SRW-B, PreWEC-A, and PreWEC-B were $15.2 \mathrm{~mm}$ prestressing strand. The targeted initial prestress (fpi) in the wall PT

69 was $239 \mathrm{MPa}$ (0.24fy) for the SRW-A and $696 \mathrm{MPa}$ (0.45fy) for SRW-B, PreWEC-A, and PreWEC-B. The targeted

70 initial prestress force was selected to maximise the wall moment capacity while keeping the axial force ratio $(\mathrm{AFR}=$

$71(\mathrm{P}+\mathrm{N}) / \mathrm{A}_{\mathrm{g}} \mathrm{f}_{\mathrm{c}}$ ) below $10 \%$ to ensure no significant crushing occurred in the wall compression toe [24]. The tendon

72 configuration and initial prestress were designed to ensure that the tendon force did not exceed the yield strength of the

73 strand until lateral drifts over 3\% were reached. The measured AFR of each wall are given in Table 1.

74 The panels were reinforced with minimum horizontal reinforcement at $100 \mathrm{~mm}$ centres, minimum vertical reinforcement

75 with the layout shown in Figure 1, and with specially designed confinement reinforcement at the wall base spaced at

$7640 \mathrm{~mm}$ centres over a height of $200 \mathrm{~mm}$ up the wall, as shown in Figure 2(a) and (b). The confinement reinforcement was

77 designed for the wall toe using the confined concrete model described by Mander et al. [25] with the maximum expected

78 compressive strain in the wall toe calculated using the simplified analysis method proposed by Aaleti and Sritharan [26].

79 To minimise damage to the wall base, an armoured wall detail and grout pocket were used, as recommended by previous

80 testing [18]. A steel angle base frame constructed from $25 \times 25 \times 5 \mathrm{~mm}$ equal angle was cast into each precast wall end for

81 additional confinement and protection of the panel edge, as shown in Figure 2(c). The wall panel was seated on a grout

$82 \mathrm{pad}$ that was located within a shallow pocket in the foundation for confinement. The wall was embedded approximately

$8310 \mathrm{~mm}$ into the grout pocket to increase the sliding shear resistance. To limit the concrete compressive strains and

84 spalling of cover concrete in the toe region, SRW-B, PreWEC-A and PreWEC-B had a foam strip across the width of the

85 cover region $(15 \mathrm{~mm}$ ) glued at each wall end, as depicted in Figure 2(d). It is important to note that use of the foam

86 effectively shortens the length of the wall by $30 \mathrm{~mm}$ to $770 \mathrm{~mm}$. 
87 PreWEC-A and PreWEC-B consisted of identical precast concrete wall panels to SRW-B with the addition of two post-

88 tensioned end columns constructed from concrete filled square steel hollow sections (SHS) with a width, length and

89 thickness of $125 \times 125 \times 5 \mathrm{~mm}$. The targeted initial PT force of the columns was $220 \mathrm{kN}$ per column using a $26 \mathrm{~mm}$

90 diameter stress-bar with an unbonded length of $3000 \mathrm{~mm}$ for all PreWEC tests. The targeted initial PT force in the

91 columns was selected using the design procedure published by Aaleti and Sritharan [23]. The O-connectors were placed

92 across the wall-to-column joint, welded to the SHS and steel plates embedded into the precast concrete wall panel.

93 Appendix B of the New Zealand Concrete Structures Standard (NZS 3101:2006) [22] outlines special provisions for the

94 design of ductile jointed precast concrete structural systems. In an attempt to ensure self-centring, NZS 3101 states that

95 the ratio $(\lambda)$ of the moment contribution from the restoring forces (PT and axial load) to the energy dissipating elements

96 must be greater than or equal to the overstrength factor for the energy dissipating devices. However, previous research

97 has found that this procedure is inadequate to ensure that self-centring is achieved when realistic PT concrete systems are

98 subjected to earthquake loads [20,27]. Despite these limitations, $\lambda$ is still a useful property that represents the relative

99 amount of energy dissipation in PT systems. The number of O-connectors for PreWEC-A and PreWEC-B were chosen

100 such that the specimen with the higher number of connectors would have a moment contribution from the O-connectors

101 less than but close to that provided by the PT at the design lateral drift. As presented in Table 1, PreWEC-A and

102 PreWEC-B had four and six O-connectors per joint, respectively. For design lateral drifts between 1-2\%, the $\lambda$ ratio for

103 PreWEC-A and PreWEC-B remained approximately constant at 1.8 and 1.25 , respectively, which are greater than the

104 minimum value of 1.15 prescribed in Appendix B of NZS 3101:2006.

Table 1 - Wall specifications

\begin{tabular}{|c|c|c|c|c|c|c|c|c|}
\hline \multirow[t]{2}{*}{$\begin{array}{c}\text { Wall } \\
\text { Label }\end{array}$} & \multirow[t]{2}{*}{$\begin{array}{l}\text { Tendon } \\
\text { type }\end{array}$} & \multicolumn{2}{|c|}{$\begin{array}{c}\mathbf{f}_{\mathbf{p i}} \\
(\mathbf{M P a})\end{array}$} & \multirow[t]{2}{*}{$\begin{array}{c}\boldsymbol{f}_{c}^{\prime} \\
(\mathbf{M P a})\end{array}$} & \multirow{2}{*}{$\begin{array}{c}\boldsymbol{f}_{\boldsymbol{g}}^{\prime} \\
(\mathbf{M P a})\end{array}$} & \multicolumn{2}{|c|}{$\begin{array}{c}\operatorname{AFR}\left(\mathbf{f}_{\mathrm{c}} / \mathbf{f}^{\prime}{ }_{\mathrm{c}}\right) \\
(\%)\end{array}$} & \multirow{2}{*}{$\begin{array}{c}\text { O - Connectors } \\
\text { per joint }\end{array}$} \\
\hline & & Target & Achieved & & & Target & Achieved & \\
\hline SRW-A & Bar & 239 & 233 & 32.0 & $60.0^{*}$ & 2.0 & 2.49 & - \\
\hline SRW-B & Strand & 696 & 686 & 35.0 & 36.3 & 7.5 & 9.53 & - \\
\hline $\begin{array}{c}\text { PreWEC-A } \\
(1 / 2)\end{array}$ & Strand & 696 & $694 / 705$ & 42.7 & 60.2 & 7.5 & $7.84 / 7.96$ & 4 \\
\hline PreWEC-B & Strand & 696 & 710 & 40.7 & 48.4 & 7.5 & 8.4 & 6 \\
\hline
\end{tabular}




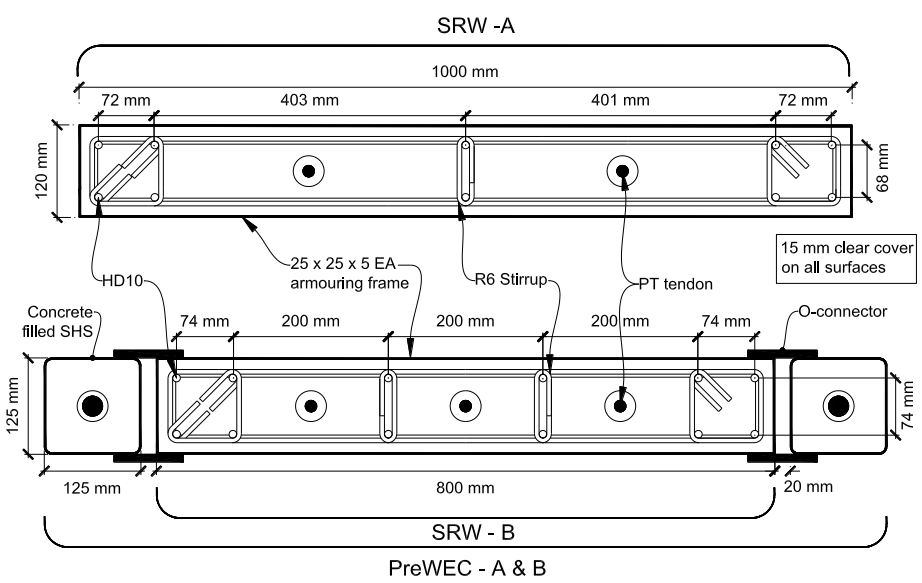

Figure 1 - Wall cross section details

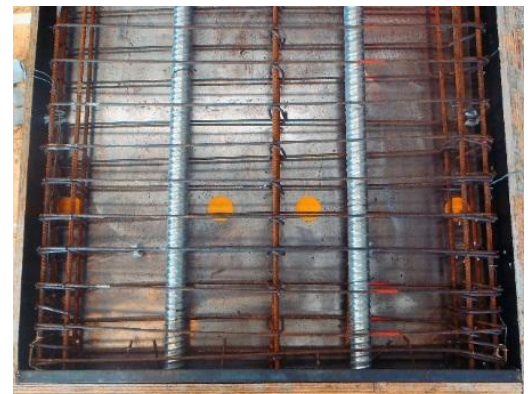

a) SRW-A

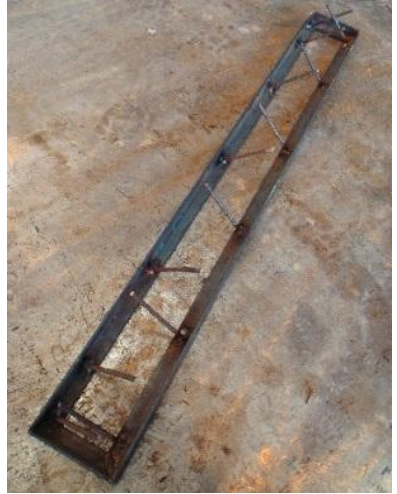

c) Armouring angle frame

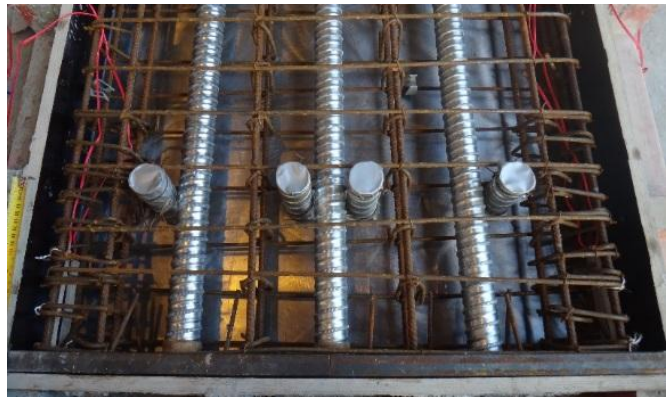

b) SRW-B and PreWEC-A/B

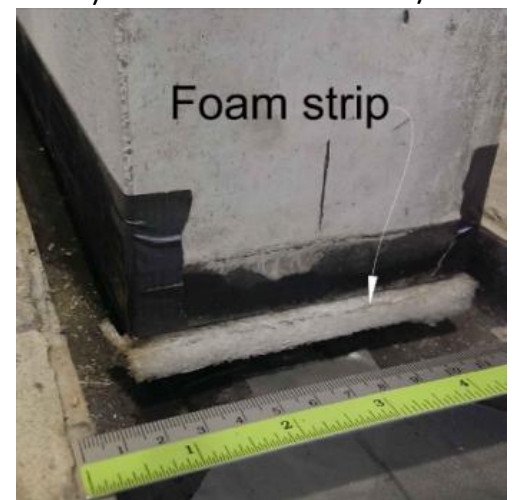

d) Wall placement (SRW-B)

Figure 2 - Base of wall reinforcement and construction details

\subsection{Material properties}

112 In accordance with New Zealand Standards [28], test cylinders and cubes were used to determine the compressive

113 strength of each wall and the grout pad. The measured concrete $\left(f_{c}^{\prime}\right)$ and grout $\left(f_{g}^{\prime}\right)$ strengths on the day of testing for each

114 wall are provided in Table 1. As stated earlier, both $15 \mathrm{~mm}$ high strength bar and $15.2 \mathrm{~mm}$ strand were used for the wall

115 PT tendon and three tensile tests per PT tendon were conducted. All steel tensile testing was conducted in accordance

116 with the metallic materials tensile testing standard [29]. The $15 \mathrm{~mm}$ stress bar had an average measured yield stress of

$117997 \mathrm{MPa}$, ultimate stress of $1156 \mathrm{MPa}$, modulus of elasticity of $201 \mathrm{GPa}$, and cross-sectional area of $177 \mathrm{~mm}$. The

$11815.2 \mathrm{~mm}$ strand had an average measured yield stress of $1540 \mathrm{MPa}$, modulus of elasticity of $199.5 \mathrm{GPa}$, cross-sectional 
120 on the mill test certificate due to premature fracture of strand at the anchorage. Premature fracture of strand at anchorages

121 was found to be a common problem by Walsh and Kurama [30] for monostrand anchorages. In this case the strand failure

122 was not considered critical as the initial prestress was selected to prevent the strand yielding during the cyclic testing.

123 The concrete filled steel tube had an average concrete compressive strength of $38.2 \mathrm{MPa}$ determined on the day of testing

124 of the first PreWEC wall, this value is therefore a minimum for later tests as the same undamaged columns were reused

125 for all tests. The wall vertical and horizontal reinforcement consisted of HD10 (10 mm diameter grade $500 \mathrm{MPa}$

126 deformed bar) and R6 (6 mm diameter grade $300 \mathrm{MPa}$ round bar) bars respectively.

\section{$2.3 \quad$ O-Connector properties}

128 The O-connector concept was originally developed by Henry et al. [19] and subsequently used during the first PreWEC 129 cyclic test [18]. The O-connectors used in the testing of all PreWEC systems herein are referred to as O-connector 130 geometry type "O1" as described in Twigden and Henry [31]. The O-connectors were laser cut out of $10 \mathrm{~mm}$ thick mild 131 steel plate with the geometry shown in Figure 3(a). As reported in Twigden and Henry [31] a component test was 132 performed on the O-connector using the setup shown in Figure 3(b). The test setup consisted of four O-connectors which 133 provided an average connector response for the applied loading which consisted of a displacement protocol that was 134 identical to the relative vertical displacement of the column to wall measured during the PreWEC-A2 cyclic test. The 135 measured force-displacement response of a single O-connector for the applied relative vertical displacement is shown in 136 Figure 3(c). The connector strength was derived by dividing the total measured force of the setup by four. A stable force137 displacement response was observed until fracture of the O-connectors initiated during the second cycle to $22 \mathrm{~mm}$ 138 vertical displacement, which corresponded to $3 \%$ lateral wall drift during the PreWEC-A test.

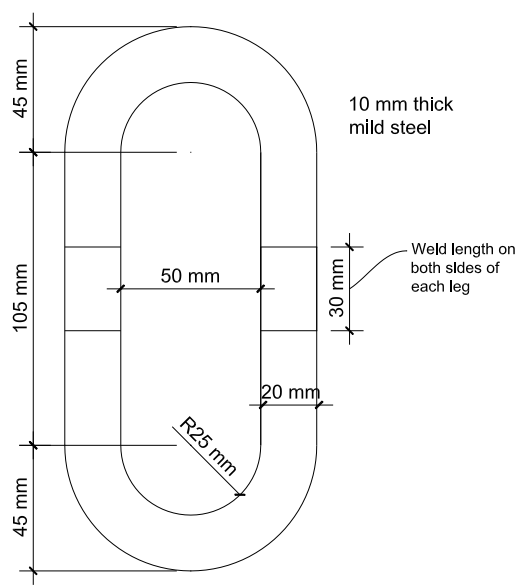

(a) O-connector dimensions

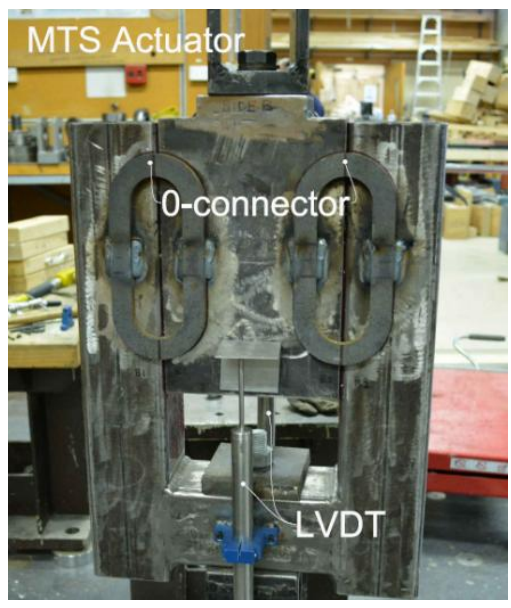

(b) Test setup

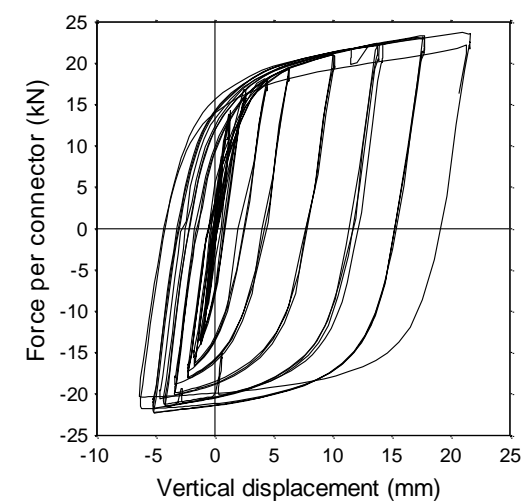

(c) Force-displacement behaviour 


\subsection{Test setup}

141 A schematic and photo of the typical test setup and instrumentation of a PreWEC test is presented in Figure 4. The test

142 setup for the SRW tests was identical except without the columns and O-connectors. The wall panels were erected onto a

143 foundation block that was post-tensioned to the strong floor. A $40 \mathrm{~mm}$ deep by $160 \mathrm{~mm}$ wide shallow pocket which ran

144 the length of the wall system was provided in the top of the foundation. The wall was initially supported on small $30 \mathrm{~mm}$

145 high shims and high strength grout was flowed under the wall to fill the pocket and provide an even bearing surface at the

146 wall-to-foundation interface.

147 A concrete block was attached and grouted on top of the wall and steel beams were placed adjacent to the block to

148 prevent out-of-plane deformations of the wall. To perform the pseudo-static cyclic testing, a hydraulic actuator was

149 attached through the loading block at a height of $3150 \mathrm{~mm}$ for SRW-A and $3000 \mathrm{~mm}$ for SRW-B, PreWEC-A, and

150 PreWEC-B from the wall base. The PT tendons of the walls and columns were anchored between the foundation and top

151 block and remained unbonded over the entire height. The typical unbonded length of wall tendons for SRW-B, PreWEC-

152 A and PreWEC-B was $3600 \mathrm{~mm}$ and $3900 \mathrm{~mm}$ for SRW-A. The typical strand anchorage is shown in Figure 3(c). A

153 specially designed and manufactured threaded barrel with round nut were used to finely adjust the initial tendon stress

154 and de-stress without having to release the wedges from the barrel. For SRW-B, PreWEC-A and PreWEC-B the top 155 concrete block weighed $31.35 \mathrm{kN}$ and for SRW-A the top concrete block weighed $20.11 \mathrm{kN}$. The top block provided 156 additional mass for dynamic tests that were performed using the same test setup, but are not reported herein. Due to the slightly different setup between SRW-A and the other test walls SRW-A had a centre of mass, including wall mass, of $2841 \mathrm{~mm}$ from the base of the wall while SRW-B, PreWEC-A and PreWEC-B had a centre of mass of $2660 \mathrm{~mm}$ from the base of the wall

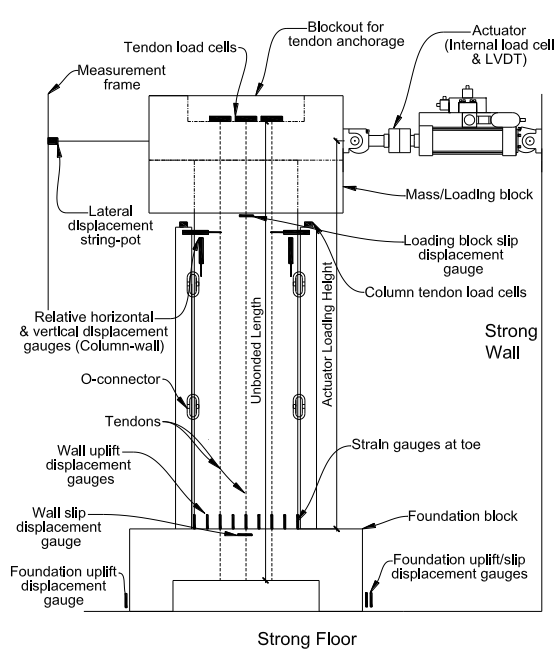

a) Test setup/instrumentation schematic

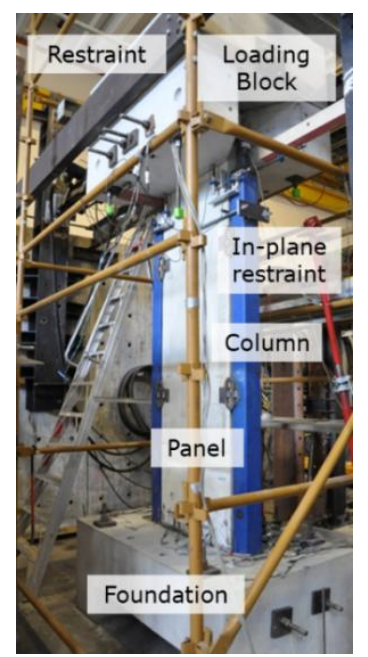

b) Photo of test setup (PreWEC)

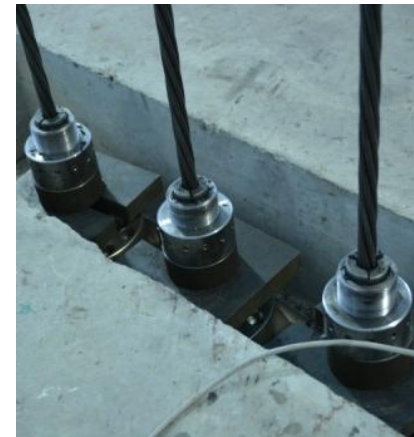

c) PT anchorage setup 


\subsection{Load protocol}

162 The loading protocol for the test was developed in accordance with ACI guidelines for the acceptance criteria for 163 unbonded PT concrete walls, ACI ITG-5.1 [32]. For SRW-B, PreWEC-A and PreWEC-B, three force based cycles to a 164 maximum of 0.6 times the decompression moment were applied first followed by displacement controlled cycles up to a 165 maximum of 3\% lateral drift, as shown in Figure 5. For SRW-A, a maximum lateral drift of $2 \%$ was applied to prevent 166 yielding of the tendons.

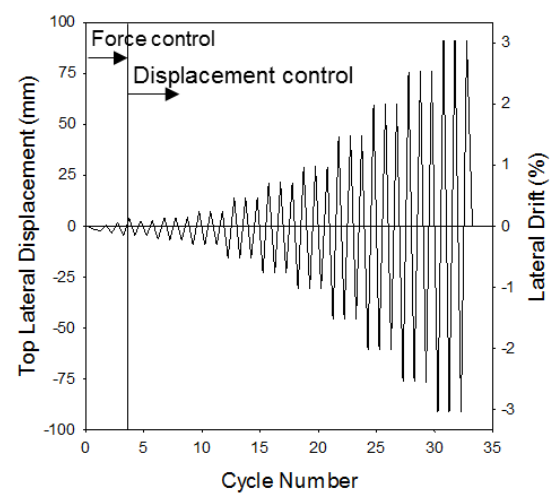

Figure 5 - Load protocol

\subsection{Instrumentation}

The walls were extensively instrumented as depicted in Figure 4(a). Displacement gauges were placed at the base of the wall to measure uplift. Additional displacement gauges were placed at the foundation-floor and wall-loading block interface to monitor slip and unintended uplift of the foundation. A string-pot was used to measure the top lateral displacement at the actuator height. Load cells were used to measure the lateral load in the actuator as well as the wall and column PT tendon forces. For the PreWEC tests, LVDTs (Linear Variable Differential Transformer) were used to measure the relative vertical and horizontal displacements between the wall and each end column.

Strain gauges were placed both inside and on the surface of the concrete at the wall toe to measure the strain demand. Embedded concrete strain gauges were cast in the confined concrete region of each wall toe for each test. The two embedded gauges for SRW-A had a gauge length of $30 \mathrm{~mm}$ and were placed $10 \mathrm{~mm}$ in from the wall compression edge, $65 \mathrm{~mm}$ up from the wall base and $40 \mathrm{~mm}$ from each side. For SRW-B, PreWEC-A1, PreWEC-A2 and PreWEC-B, embedded strain gauges with a $60 \mathrm{~mm}$ gauge length were used. For SRW-B the two embedded gauges were placed $10 \mathrm{~mm}$ in from the wall compression edge, $25 \mathrm{~mm}$ up from the wall base and $42 \mathrm{~mm}$ in from each side at each toe. For PreWEC-A and PreWEC-B, the two embedded gauges in each wall toe were placed $30 \mathrm{~mm}$ in from the wall compression edge, $35 \mathrm{~mm}$ up from the wall base and $45 \mathrm{~mm}$ in from each side at each toe. Surface mounted strain gauges were also placed on the end of each wall panel for each test. The SRW-A surface strain gauges were $30 \mathrm{~mm}$ long and placed $60 \mathrm{~mm}$ up from the wall base and $43 \mathrm{~mm}$ in from each side. The surface strain gauges were $60 \mathrm{~mm}$ long for SRW-B, 
186 PreWEC-A, and PreWEC-B and were placed $60 \mathrm{~mm}$ up from the wall base and $35 \mathrm{~mm}$ in from each side. All

187 measurements reported are to the centre of the strain gauge.

\section{$188 \quad 3 \quad$ TEST OBSERVATIONS}

189 The four test walls all performed well with uplift occurring at the wall base when compared to the distributed cracking 190 expected from traditional reinforced concrete walls. The condition of PreWEC-B at 3\% lateral drift is shown in Figure 191 6(a), which was also indicative of the typical condition for all the test walls at that drift level. No flexural cracks were 192 observed in the wall panels and no significant crushing occurred in the compression toe for any of the tests. Only a minor 193 amount of spalling was observed in the wall toes at drifts greater than $2 \%$ and no bending of the steel angle armouring 194 frame used for confinement was observed. Additionally, no slip was observed between the wall and foundation during any of the tests. The observed damage was cosmetic and expected to be easily repairable following an earthquake.

The armouring at grout pocket detail at the wall base worked well with damage to the wall toes isolated to a small area and no significant crashing of the grout. A close up of the toe damage at the end of each test is shown in Figure 7. There is only a small increase in spalling between SRW-A and SRW-B despite SRW-B having almost four times the AFR. The foam strip used in the corner of walls SRW-B, PreWEC-A and PreWEC-B was successful in limiting the spalling of the wall toe, with similar damage observed for all four test walls despite SRW-B, PreWEC-A and PreWEC- B walls having much higher AFR's than SRW-A.

202 The wall and end columns rocked independently during the PreWEC tests and imposed a vertical deformation on the O203 connectors at the wall-to-column joint. The deformed shape of one of the O-connectors in PreWEC-B at 3\% lateral drift 204 is shown in Figure 6(b). As expected, the O-connector behaviour was dominated by flexural yielding of legs up until 205 failure which occurred during cycles to $3 \%$ lateral drift. The displacement capacity and failure mode of the O-connectors 206 was similar to that observed during the component tests discussed earlier. Despite failure of the connectors occurring at $2073 \%$ lateral drift for most PreWEC tests, it should be noted that the O-connectors can be designed to achieve greater 208 displacement capacity depending on their geometry and steel grade $[19,33]$.

209 Two cyclic tests were performed on the PreWEC-A wall. The first test (PreWEC-A1) relied solely on the O-connectors 210 to connect the wall to the end columns. During this test it was observed that the columns were pushed and pulled with the 211 wall by the O-connectors causing horizontal compression and tension to be imposed on the O-connectors. As a result 212 larger than expected horizontal displacements were imposed on the O-connectors resulting in premature failure during 213 the 2.5\% lateral drift cycles. It should be noted that the O-connectors were not designed to transfer horizontal forces to tie 
214 the wall and columns components and in a building application the floor diaphragm would serve this function,

215 minimising horizontal deformations of the O-connector and forcing the wall and columns to move together. Following

216 the first test, the fractured O-connectors were removed and new connectors were welded onto the PreWEC-A wall. An

217 in-plane lateral restraint, as shown in Figure 4(b), was added during the second test (PreWEC-A2) to simulate the floor

218 diaphragm and enable the end columns to laterally displace with the wall without relying on the O-connectors. Use of the

219 restraint for PreWEC-A2 resulted in the O-connectors achieving their design displacement, with failure occurring during

220 the 3\% lateral drift cycles as expected from the component test. The end column restraints were also used successfully

221 during the PreWEC-B test, with the columns displacing laterally with the wall and O-connector failure again occurring

222 during cycles to $3 \%$ lateral drift.

223 Struts or restraints were also attached between the wall and end columns during the PreWEC test reported by Aaleti et al.

224 [34], but were later found to be not required during the test. In contrast the restraint was required during the tests reported

225 herein due to the relative strengths of the wall, end columns, and O-connectors. A horizontal force of $0.86 \mathrm{kN}$ per O-

226 connector was required to pull the end column to 2\% drift during the PreWEC-A test compared to a horizontal force of

$2270.24 \mathrm{kN}$ per O-connector for the Aaleti et al. PreWEC test. Due to the different connector size, these horizontal forces

228 equated to $3.6 \%$ and $0.5 \%$ of the O-connector vertical force capacity for the PreWEC-A and Aaleti et al. PreWEC tests

respectively. These calculations demonstrate that a seven times greater demand was placed on each O-connector during

230 the PreWEC-A test compared to the Aaleti et al. PreWEC test. Therefore the requirement of the restraints is a function of

231 the relative strengths of the end column and connectors, and should be considered during the design of the O-connectors.

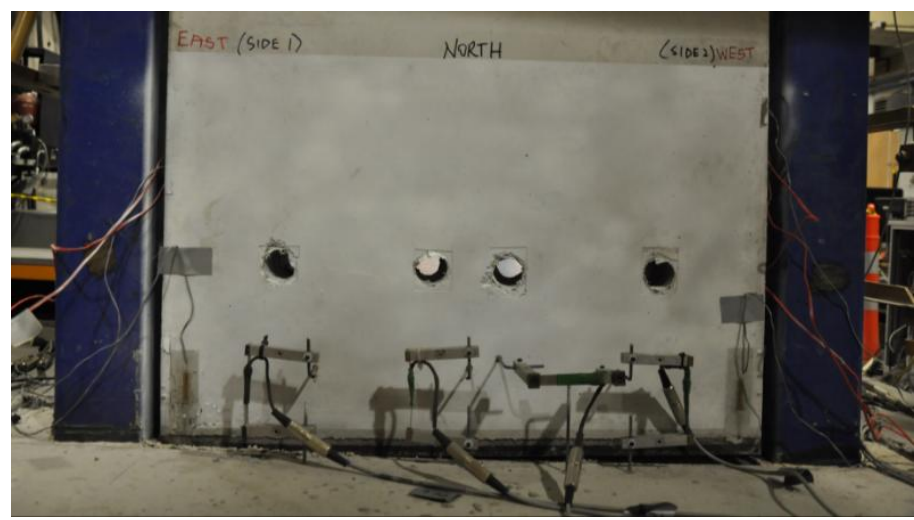

(a) Condition of wall during uplift at 3\% drift for PreWEC-B

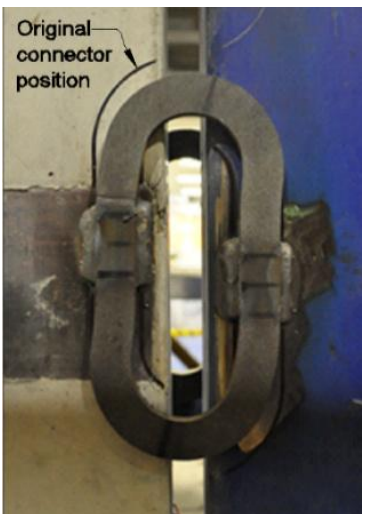

(b) O-connector at 3\% drift for PreWEC-B 


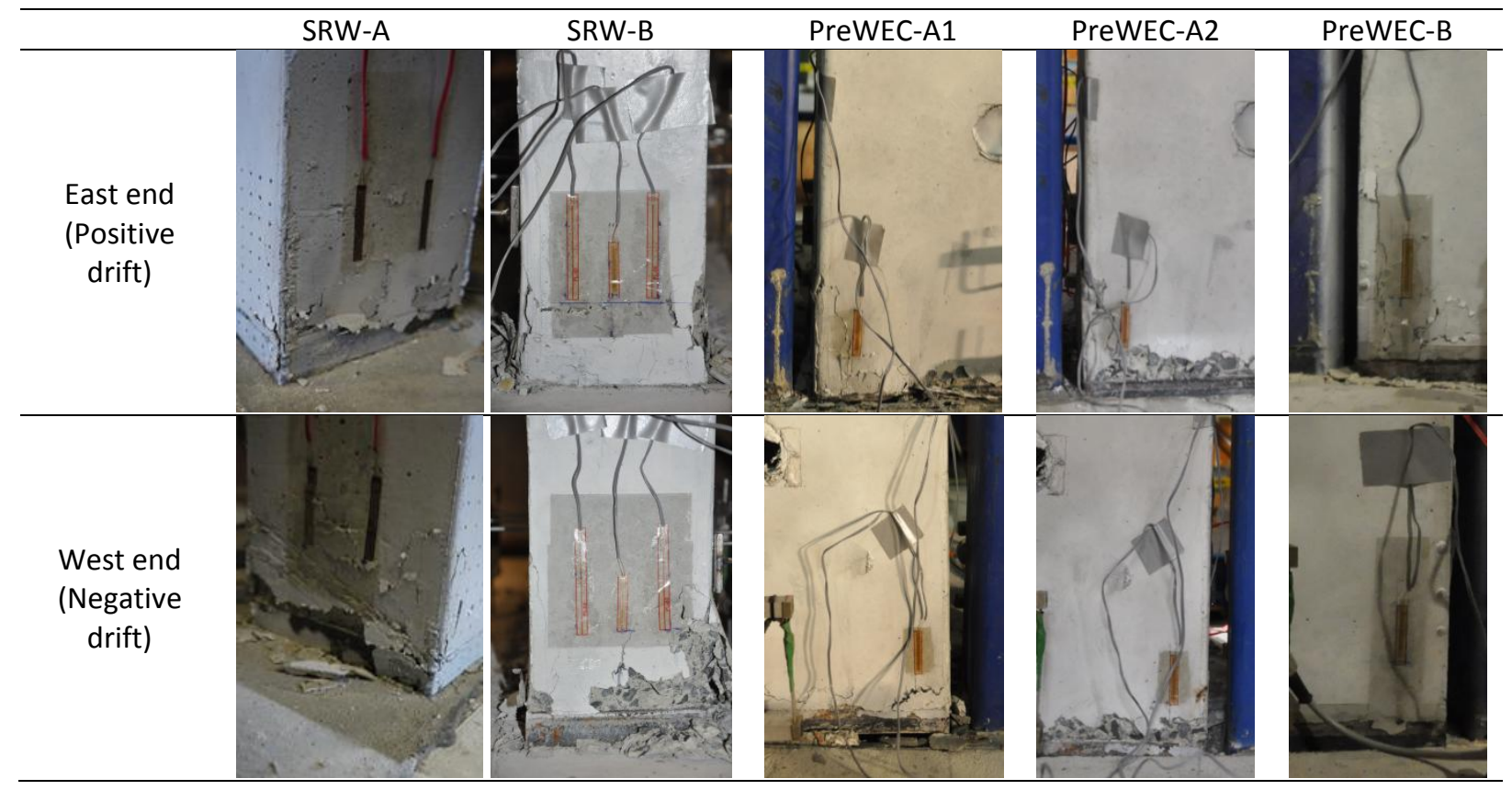

Figure 7 - Observations of wall toe damage for all tests

\section{RESULTS AND DISCUSSION}

\section{$235 \quad 4.1 \quad$ Force displacement response}

236 The measured lateral force-displacement response for each of the four test walls are shown in Figure 8. The overall

237 behaviour was good with no significant strength degradation until the O-connectors started fracturing during the PreWEC

238 tests, and only minor stiffness degradation. A simplified analysis approach developed by Aaleti and Sritharan [26] was

239 used to predict the behaviour of the four test walls, and is compared against the measured experimental results in Figure

240 8. The simplified analysis method accurately captured the envelope of the global behaviour of both the SRW and

241 PreWEC systems.

242 SRW-A exhibited an imperfect bilinear elastic response with a small amount of hysteresis up until the test finished at $2 \%$

243 lateral drift. SRW-B also exhibited an imperfect bilinear response up until $2 \%$ lateral drift at which stage the unloading

244 path altered with increased hysteresis introduced into the system. The change in unloading path could be due to PT loss

245 within the system, debris becoming trapped underneath the wall, or minor inelastic concrete strains in the wall toe.

246 Both PreWEC-A1 and A2 tests resulted in a similar global force-displacement response with increased hysteresis area

247 when compared to the two SRW tests. A small amount of stiffness softening was observed for PreWEC-A2 when

248 compared to PreWEC-A1 due to the small amount of inelastic concrete strains that occurred in the wall toe during

249 PreWEC-A1. PreWEC-A2 achieved a more desirable force-displacement response in comparison to PreWEC-A1 as the

250 O-connectors fractured during the $3 \%$ lateral drift cycles instead of $2.5 \%$ lateral drift cycles due to the addition of the end 
column restraints. It is possible that some differences between PreWEC-A1 and PreWEC-A2 were due to the presence of

252 the restraint, discussion on this is provided where relevant in the following sections. As shown in Figure 8(d), PreWEC-B

253 exhibited increased hysteresis area when compared to the SRW tests and the PreWEC-A system due to a 50\% increase in

254 the number of connectors. Fracture of the connectors initiated at 3\% lateral drift, similar to that observed during the

255 PreWEC-A2 test. The increase in lateral strength and hysteresis from SRW-B to PreWEC-A to PreWEC-B was due to

256 the strength provided by the increasing number of O-connectors, and was accurately predicted by the Aaleti and Sritharan 257 simplified analysis method.

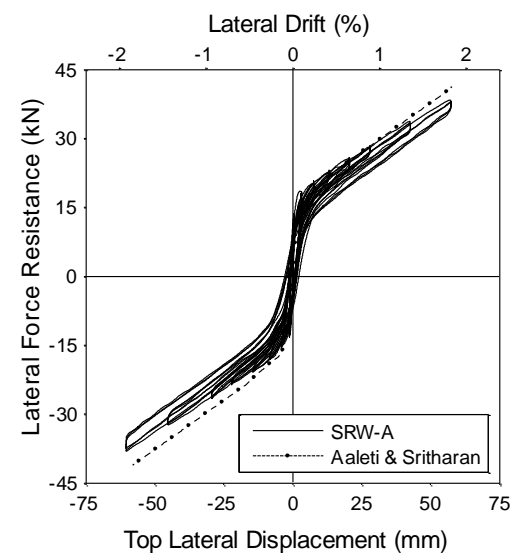

(a) SRW-A

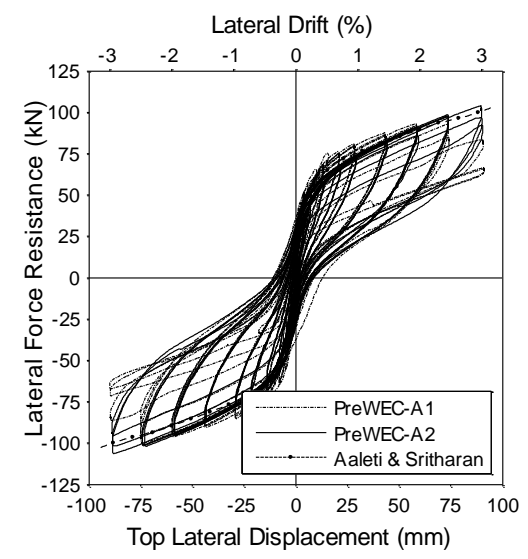

(c) PreWEC-A

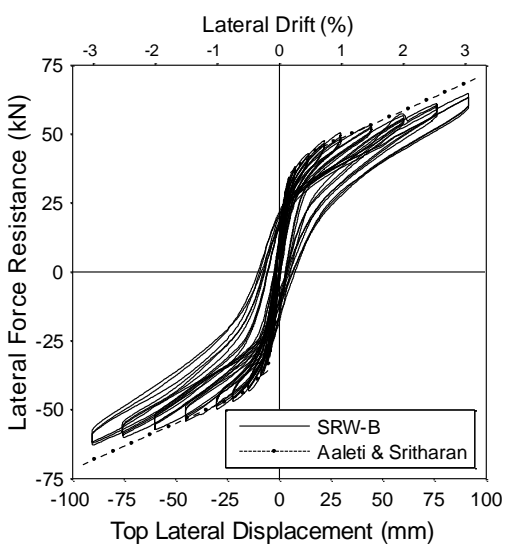

(b) SRW-B

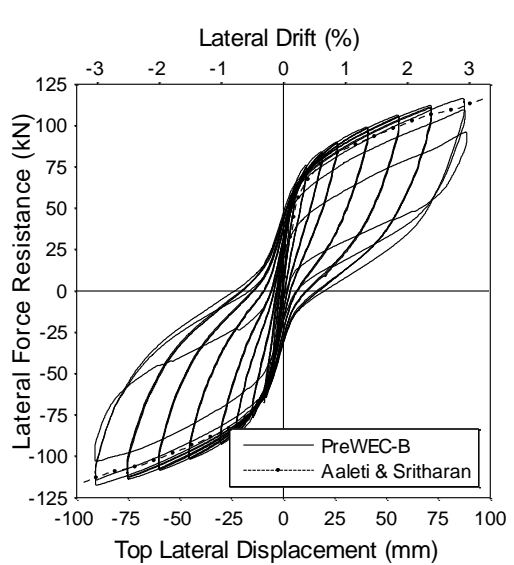

(d) PreWEC-B

Figure 8 - Measured lateral force-displacement responses for each test

\section{$259 \quad 4.2 \quad$ Initial stiffness}

260 The stiffness of structural walls is important when calculating the fundamental period of a structure. The initial stiffness of the four test walls was determined from the force based cycles applied at the start of the loading protocol. A best fit linear trend was used to find the slope (initial stiffness) of the force displacement loading curve for the largest cycle below decompression of each wall system. As presented in Table 2, the measured initial stiffness of SRW-A, SRW-B, 
$12.19 \mathrm{kN} / \mathrm{mm}$, respectively. The effective stiffness modifier ratio of PreWEC-A2 is not comparable as the wall had already been subjected to the PreWEC-A1 test. During the force based cycles no uplift occurred at the wall base which implies that the expected lateral stiffness should theoretically be calculated based on the gross section moment of inertia (Ig). A prediction of the initial stiffness of each wall is also presented in Table 2, and was calculated assuming a lateral stiffness ( $\mathrm{k}$ ) equal to the sum of $3 \mathrm{EIg} / \mathrm{h} 3$ for each component (walls and end columns), where $\mathrm{E}$ is the modulus of elasticity, I the moment of inertia and $\mathrm{h}$ the height of the applied load [35]. The calculation assumed a concrete modulus of elasticity (Ec) equal to $4700 \sqrt{f_{c}^{\prime}}$, where $\mathrm{f}_{\mathrm{c}}^{\prime}$ is the compressive strength of concrete in MPa. The height used for the column stiffness calculation was the height of load application. The final row in Table 2 is effective stiffness modifier which is the measured initial stiffness divided by the predicted initial stiffness. For all walls use of the gross section properties significantly overestimates the initial stiffness. Despite the two SRW specimens having different section properties they had similar effective stiffness modifier ratios of 0.64 and 0.61 and the two undamaged PreWEC specimens PreWEC-A1 and PreWEC-B had similar effective stiffness modifier ratios of 0.79 and 0.77 .

Table 2 - Initial stiffness of each test specimen

\begin{tabular}{lcccc}
\hline & $\begin{array}{c}\text { SRW- } \\
\text { A }\end{array}$ & SRW-B & PreWEC-A1 & PreWEC-B \\
\hline Measured initial stiffness $\left(\mathrm{K}_{\mathrm{i}(\mathrm{m})}\right) \mathbf{k N} / \mathbf{m m}$ & 16.36 & 8.89 & 12.90 & 12.19 \\
& & & 16.42 & 15.84 \\
Predicted initial stiffness $\left(\mathrm{K}_{\mathrm{i}(\mathrm{p})}\right) \mathbf{k N} / \mathbf{m m}$ & 25.52 & 14.69 & 0.79 & 0.77 \\
Effective stiffness modifier $\left.\left(\mathrm{K}_{\mathrm{i}(\mathrm{m})} / \mathrm{K}_{\mathrm{i}(\mathrm{p})}\right)\right)$ & 0.64 & 0.61 & 0.79 \\
\hline
\end{tabular}

\section{$278 \quad 4.3 \quad$ Equivalent viscous damping}

279 Equivalent viscous damping (EVD) is used as a measure of performance as it is essential to displacement based design 280 procedures commonly used for unbonded PT structures. The EVD calculated from the force-displacement hysteresis 281 response for each cycle of the five wall tests is shown in Figure 9(a). Both the SRW specimens had relatively low EVD 282 in comparison to the PreWEC systems due to the lack of energy dissipating O-connectors. The two SRW specimens had 283 a similar amount of EVD up until 1\% lateral drift, after which point SRW-B had a slight increase in EVD due to higher 284 compressive strains. SRW-B is expected to have higher compressive strains due to the higher AFR of 9.53\% compared to $2852.49 \%$ for SRW-A. The EVD for the two SRW remained between 3-5\% throughout the tests. The difference in EVD 286 between PreWEC-A1 and A2 was attributed to two sources, firstly the energy dissipation from irrecoverable inelastic 287 strains that had already been imposed on the wall specimen during the A1 test and secondly, the restraint included in the 288 A2 test could have caused lower EVD due the reduced horizontal deformation on the O-connector and therefore lower 289 EVD. The EVD at $2 \%$ lateral drift was 4.7\%, 15.8\%, 14.9\% and 17.9\% for SRW-B, PreWEC-A1, PreWEC-A2 and 

connectors. Therefore it is reasonable to assume that the EVD difference between SRW-B and the PreWEC systems is equal to the EVD contribution from the O-connectors. For the three PreWEC tests, the EVD per O-connector ranged from $1.1-1.4 \%$ at $2 \%$ drift.

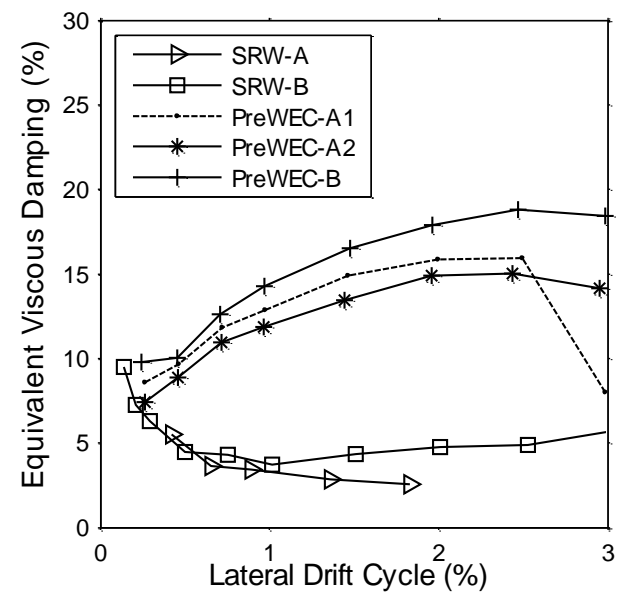

(a) Equivalent viscous damping

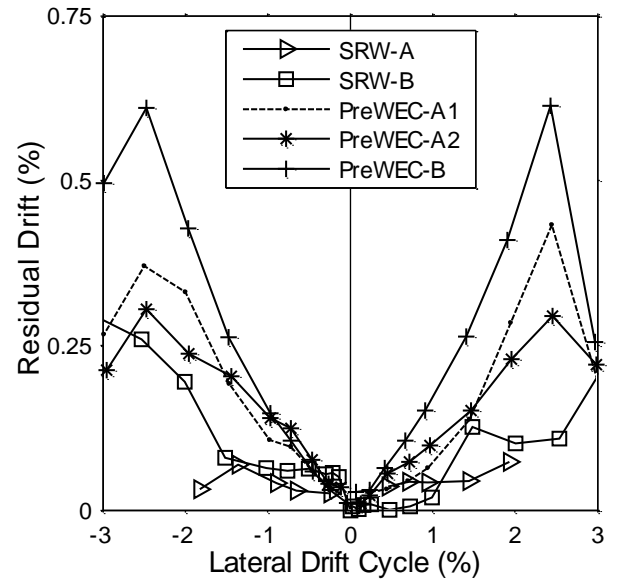

(b) Residual drifts

Figure 9 - Calculated equivalent viscous damping and residual drift for each test

\section{$295 \quad 4.4 \quad$ Residual drifts}

296 The residual drift is a critical aspect of seismic resilient design and is important to determine if the self-centring objective has been achieved. For the pseudo-static tests the residual drift was defined as the displacement at zero lateral force after unloading from the first peak displacement of each cycle. These calculated residual drifts are plotted for each of the wall tests in Figure 9(b). As expected from the hysteresis response, the residual drifts increased as the lateral drift or supplementary damping increased. From the results for the two SRW systems, it is clear that a higher AFR introduced higher residual drifts due to increased compression strains in the wall toes. For the PreWEC walls the residual drift increased with an increasing number of O-connectors as the hysteresis loops become fatter. However, interesting the residual drift for the PreWEC walls decreased or recovered from $2.5 \%$ to $3 \%$ drift as the connectors started to fracture. It is important to note that the calculated residual drifts from the pseudo-static test results do not account for dynamic response and therefore do not necessarily represent the residual drifts expected following an earthquake due to the "shake-down" effect, such as that reported by Henry et al. [27]. It is also interesting to note that residual drifts of PreWEC-A1 were slightly larger than A2 at lateral drifts larger than $1.5 \%$. It is possible that this difference could be attributed to the restraint that was used for the PreWEC-A2 and not for the A1 test. Although it is difficult to quantify the effect of the restraint on the restoring force, PreWEC-A1 did demonstrate larger EVD which requires larger hysteresis loops and therefore higher residual drifts in the cyclic response. However, as explained earlier these small differences in residual were expected to be irrelevant when considering dynamic loading. 


\section{$312 \quad 4.5 \quad$ Connector behaviour}

313 The relative vertical displacement measured between each end column and the wall at the location of the top O-

314 connectors for the three PreWEC cyclic tests is presented in Figure 10(a). The relative vertical displacement between the

315 wall and end columns reached up to $23 \mathrm{~mm}$ at the end with wall uplift and up to $7 \mathrm{~mm}$ at the end of with toe

316 compression. By comparing the measured connector displacements from the PreWEC tests to that of the component test

317 shown previously in in Figure 3(c), it is proven that the O-connectors yield in both loading directions in the PreWEC

318 system. The relative vertical displacement measured between each end column and the wall was almost identical for all

319 of the PreWEC tests, which implies similar panel behaviour regardless of O-connector number.

320 Figure 10(b) presents the change in relative horizontal displacement between the wall and east column with lateral drift.

321 Only the east column is presented due to the symmetrical behaviour observed. PreWEC-A1 achieved the highest relative

322 horizontal displacement, up to $6 \mathrm{~mm}$, due to the lack of a restraint between the wall and columns. PreWEC-A2 and

323 PreWEC-B indicate significantly lower relative horizontal displacements due to the addition of the restraint between the

324 wall and columns that limited the horizontal force resisted by the O-connectors. The higher relative horizontal

325 displacement caused the early failure of the O-connectors during the PreWEC-A1 test due to the increased strain demand.

326 The effect of the increased strain demand was successfully eliminated for the PreWEC-A2 and PreWEC-B tests through

327 the addition of the restraints. Evidence of this is shown by the increased performance of the O-connectors failing during

328 the $3 \%$ lateral drift cycle for both PreWEC-A2 and PreWEC-B, and also the purely vertical displacement component test

329 presented earlier in Figure 3(c), which shows failure during the same lateral drift cycle as the PreWEC-A2 wall test.

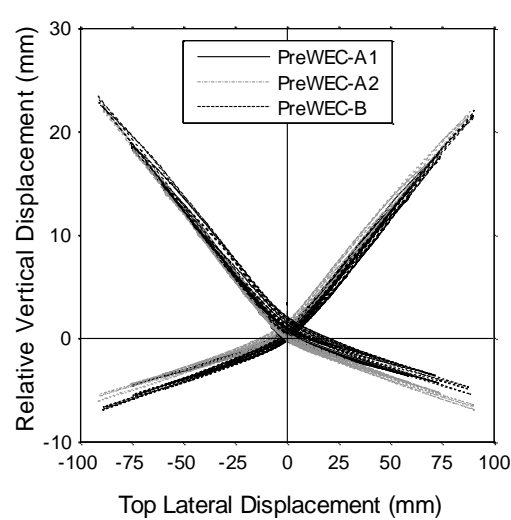

(a) Relative vertical displacement

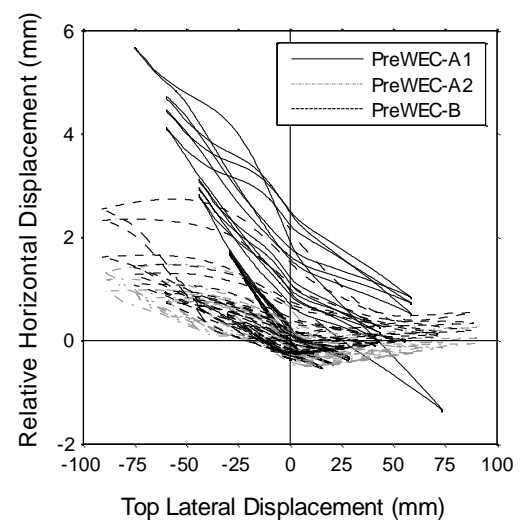

(b) Relative horizontal displacement east column

Figure 10 - Measured relative vertical and horizontal deformation of the $\mathbf{O}$-connectors

332 The measured change in total wall PT force with lateral drift for the five tests are shown in Figure 11, alongside the predicted PT force from the Aaleti and Sritharan simplified analysis method. As expected, gap opening at the wall base 


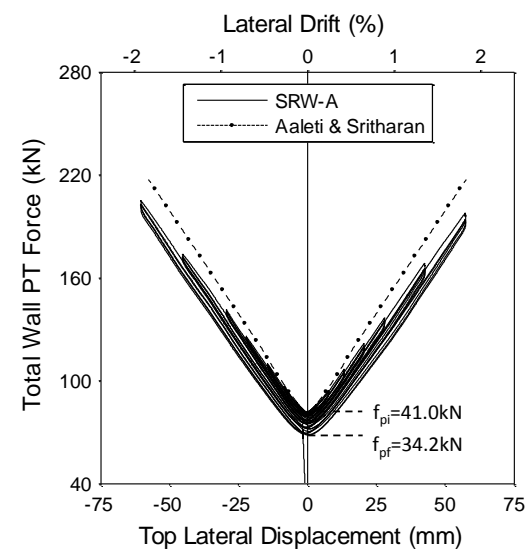

(a) SRW-A

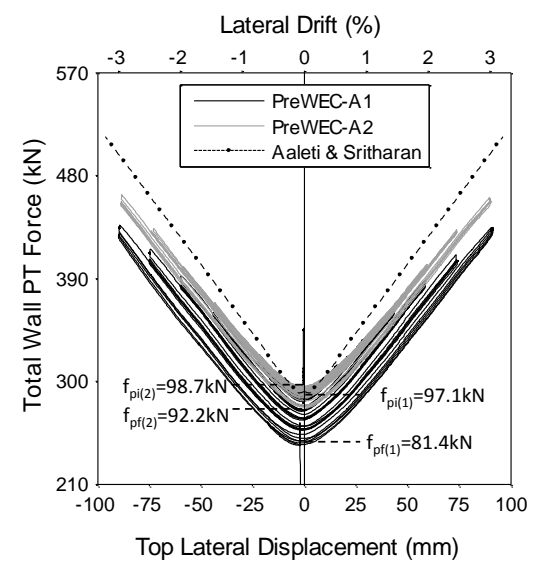

(c) PreWEC-A

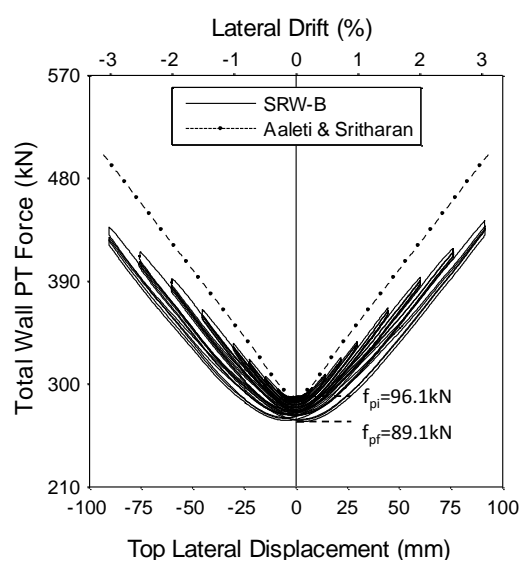

(b) SRW-B

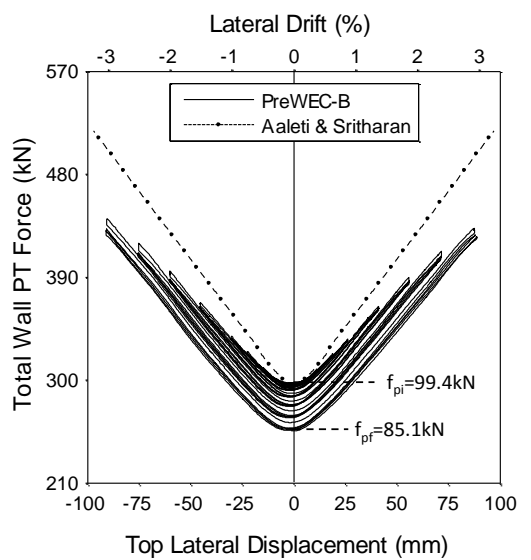

(d) PreWEC-B

Figure 11 - Measured wall PT force

338 The prestress losses were minimised by pre-seating the tendon anchorage up to a force equivalent to 0.68fy. Despite preseating the tendons and avoiding tendon yielding, prestress losses occurred consistently throughout the tests at the peak of each first drift cycle. The total prestress loss measured for SRW-A, SRW-B, PreWEC-A1, PreWEC-A2, and PreWECB was $16.6 \%, 7.3 \%, 16.2 \%, 6.6 \%$, and $14.4 \%$, respectively. As a result of these losses, the predicted tendon force was overestimated by the simplified analytical method. The losses were attributed to further wedge draw in at the anchor as the tendon force increased and wall shortening as the compression toes were subjected to inelastic strains. As depicted in Figure 11 (c), PreWEC-A2 underwent less prestress loss compared to PreWEC-A1 as the tendon anchorages had technically been pre-seated further due to the PreWEC-A1 test. PreWEC-A1 and PreWEC-B experienced similar prestress loss throughout each test, this shows a degree of predictability with the amount of prestress loss. If the entire 
348 unbonded tendon length would be equal to $2.0 \mathrm{~mm}$ for PreWEC-A1 and $1.8 \mathrm{~mm}$ for PreWEC-B. However, it is important

349 to note that the wedge draw occurs as a fixed displacement irrespective of tendon length. Therefore, the PT losses

350 observed in the four reported tests are likely to have been amplified due to the reduced wall scale and short tendon

351 length. Significantly less PT loss would be expected when the tendon length is longer in a full-scale PT wall.

\section{$352 \quad 4.7 \quad$ Neutral axis depth}

353 As previously described in section 3, all of the test walls exhibited uplift at the wall base due to rocking. An important

354 parameter to understanding the behaviour of the systems is the length of wall in contact with the foundation known as the 355 neutral axis (NA) depth. The neutral axis depth of each wall was calculated by fitting a linear function through the 356 measured uplift of the displacement gauges at the wall base. The rotation at the wall base was first calculated and then 357 the neutral axis depth determined from rotation, uplift and the known wall length. The width of foam strip at each wall 358 end of $30 \mathrm{~mm}$ total was taken into account when determining the neutral axis depth for SRW-B, PreWEC-A and 359 PreWEC-B by using an effective wall length of $770 \mathrm{~mm}$. Both the measured rotation and NA depth at the peak of each

360 lateral drift cycle are presented for each test in Figure 12. The measured NA was stable between the three cycles with no 361 NA migration for all tests. The stable NA between cycles demonstrates that no significant crushing occurred and that the 362 walls were well designed. As shown by Figure 12(a), (c), (e), and (g), the rotation was well predicted by the simplified 363 analytical method proposed by Aaleti and Sritharan [26] for all tests. The experimental NA at larger lateral drifts 364 correlated well with analytical predictions, but was typically under-predicted for lateral drifts less than $2 \%$, as 365 demonstrated by Figure 12(b), (d), (f), and (h). The average measured neutral axis depths at 3\% lateral drift for SRW-B, 366 PreWEC-A and PreWEC-B were 99.3, 82.78, and $103.6 \mathrm{~mm}$, respectively. The relatively similar NA depths demonstrate 367 that the wall behaviour appeared to be independent of the number of O-connectors when considering the differences 368 expected due to the concrete strengths, grout strengths and PT force.

\section{$369 \quad 4.8 \quad$ Concrete strains}

370 The compressive strains measured using both the surface and embedded strain gauges for all wall tests are plotted in 371 Figure 13. An example of the full cyclic response of the compressive strain versus lateral drift of an embedded strain 372 gauge in the east toe for PreWEC-A is presented in Figure 13(a). Since the strain gauge is located at the east toe there is 373 an increase in compressive strain with increasing positive lateral displacement. The observed constant strain in the 374 negative displacement direction represents the irrecoverable residual strain. The PreWEC-A2 test wall had already 375 undergone the A1 test and therefore initially measured the total residual strain at the completion of the PreWEC-A1 test. 


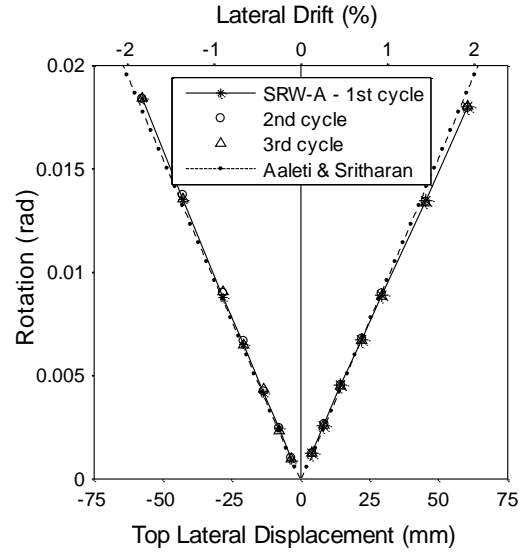

(a) SRW-A rotation

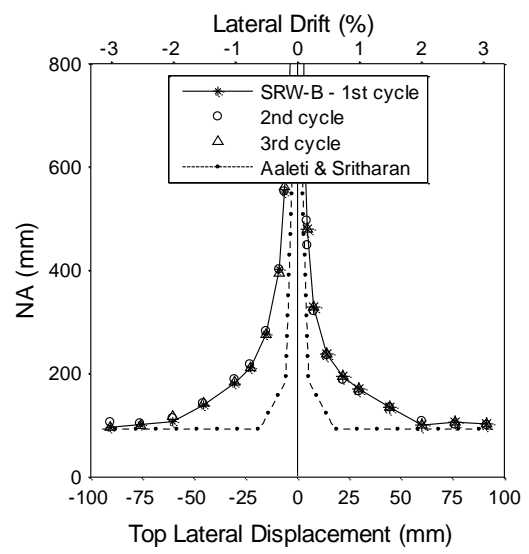

(d) SRW-B neutral axis

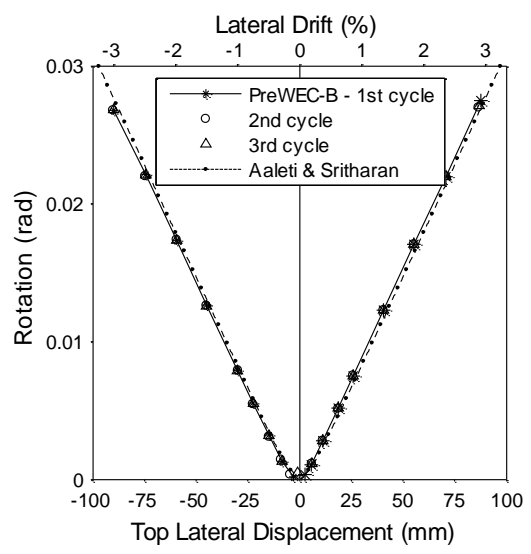

(g) PreWEC-B rotation

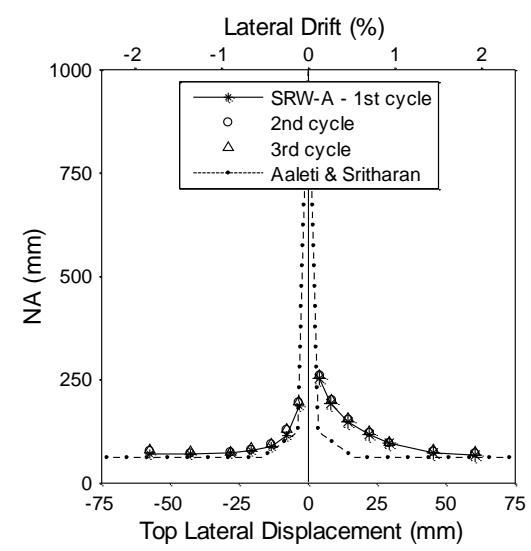

(b) SRW-A neutral axis

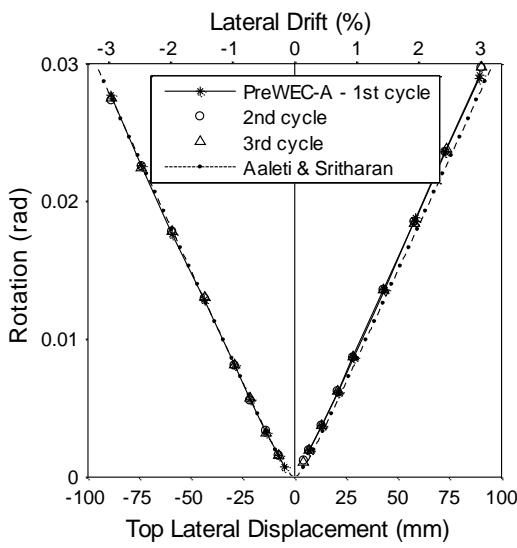

(e) PreWEC-A1 rotation

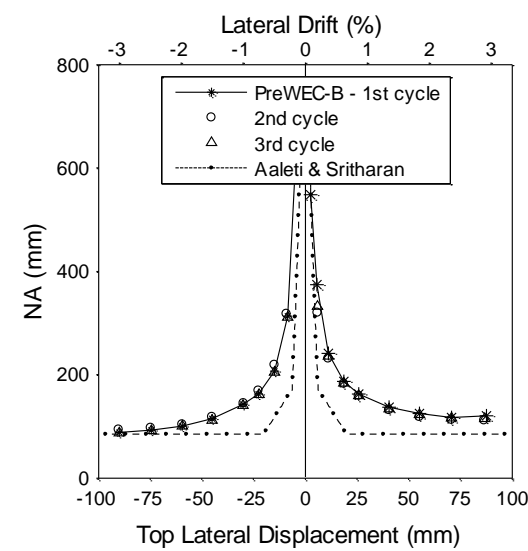

(h) PreWEC-B neutral axis

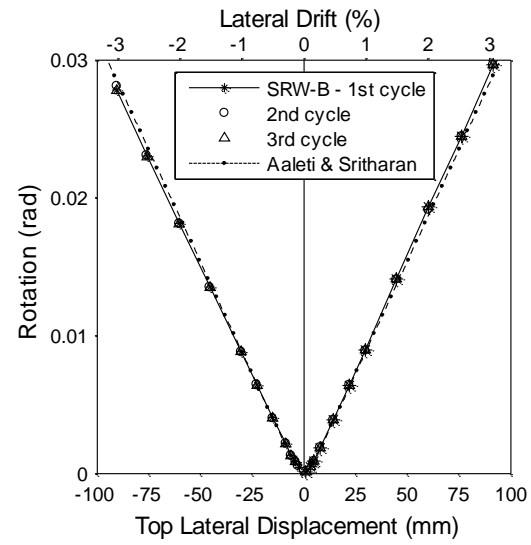

(c) SRW-B rotation

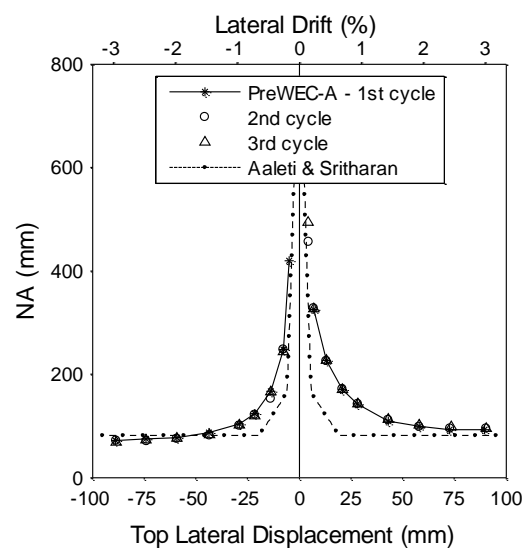

(f) PreWEC-A1 neutral axis

Figure 12 - Change in neutral axis depth and rotation with top lateral drift

To assess the maximum strain demand clearly, the envelope peak strains in the compressive toe for the first cycle to each drift level are plotted in Figure 13 (b-f) for all of the working strain gauges. For SRW-A, strains approaching 0.004 were measured by the embedded strain gauges at $2 \%$ lateral drift in the positive direction, and in excess of 0.004 in the negative loading direction. This measured compressive strain was reasonably consistent with the maximum compressive strain of 0.0064 at $2 \%$ lateral drift calculated by the simplified analysis method and used for the wall design. For SRW-B, 
PreWEC-A1, PreWEC-A2 and PreWEC-B which used the foam strips at the toes, the maximum concrete compressive

strain at 3\% lateral drift calculated using the simplified analysis method were $0.0147,0.0128,0.0129$, and 0.0133 ,

respectively. The measured compressive strains for these walls were significantly lower than this analytical prediction

ranging from 0.0025 to 0.005 . The measured surface strains were generally less than the concrete crushing strain of

0.003, which correlated well the minimal damage observed in the wall toe and proved that the walls were well designed

and that the foam strip was successful in minimising compressive strains and spalling of the cover concrete in the wall

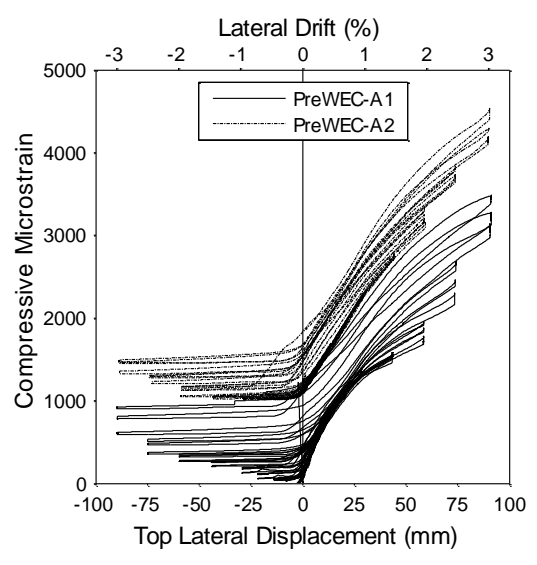

(a) PreWEC-A Embedded strain gauge (East)

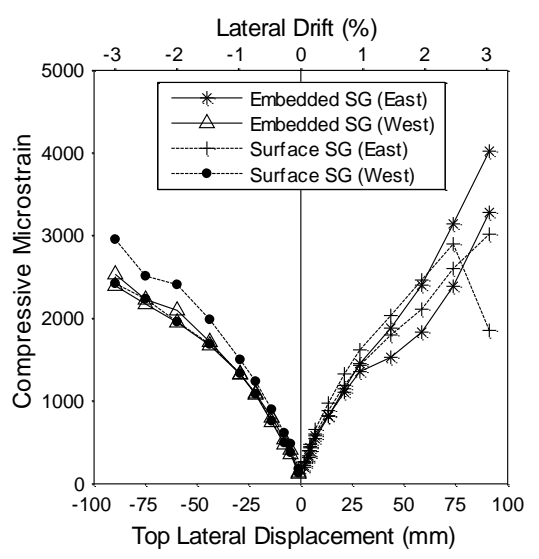

(d) PreWEC-A1

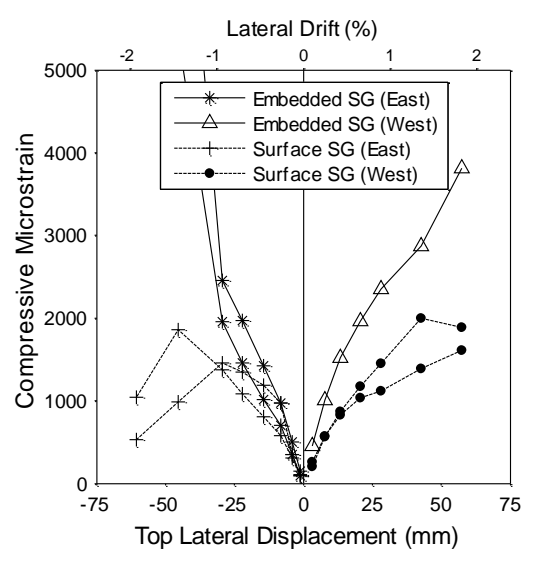

(b) SRW-A

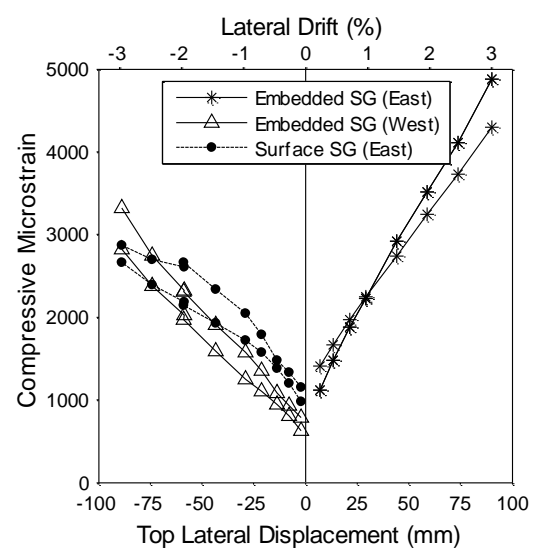

(e) PreWEC-A2

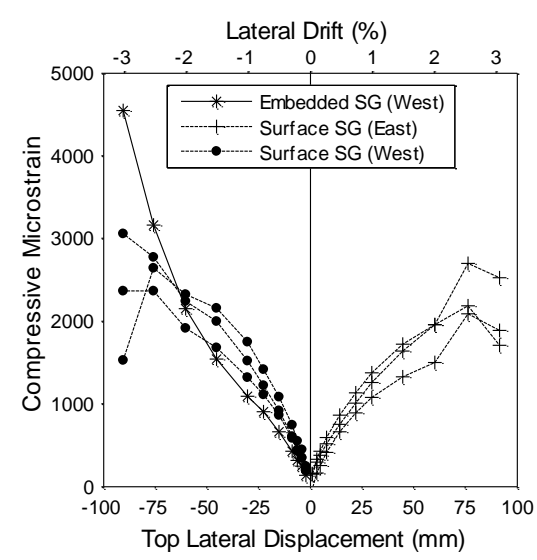

(c) SRW-B

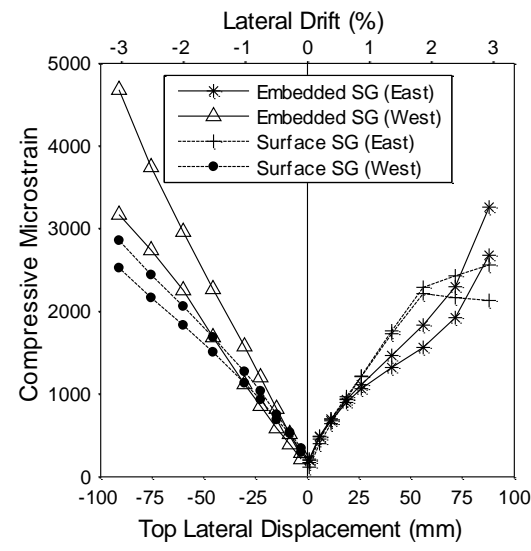

(f) PreWEC-B

Figure 13 - Measured strain versus lateral drift

391 A comparison of the average measured surface strain at each wall end for the SRW-B, PreWEC-A1, PreWEC-A2 and

392 PreWEC-B tests is shown in Figure 14. These walls provided a valid comparison of strains as the same dimensions were 393 used and foam strips were used for all four walls. The average measured surface strain for walls SRW-B, PreWEC-A1 394 and PreWEC-B were similar in amplitude and followed a consistent trend with increasing lateral drift. Thus the 


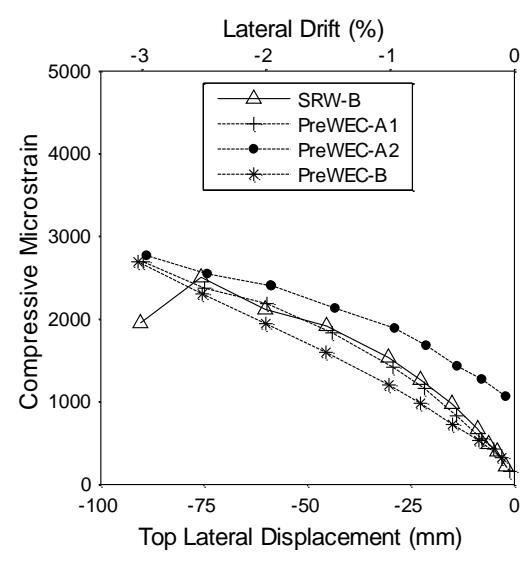

(a) West wall end

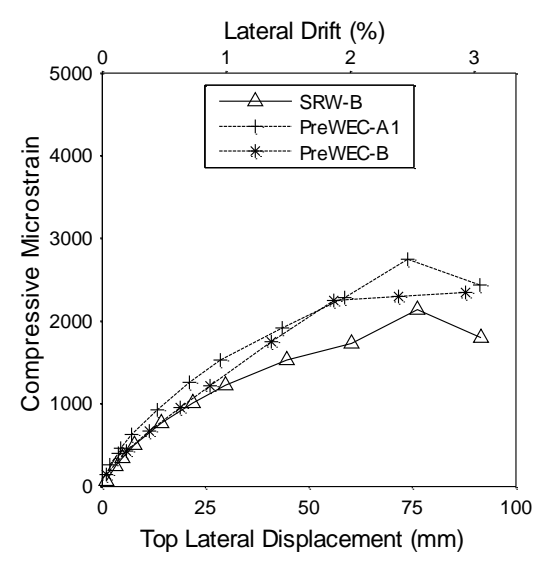

(b) East wall end

Figure 14 - Average measured strain versus lateral drift

\section{INFLUENCE OFO-CONNECTORS}

399 The PreWEC system was designed so that the O-connectors would yield in both directions of loading as both uplift and compression occurred at the ends of the wall. By undergoing a full cyclic hysteresis the O-connectors can dissipate

401 significant energy and improve the seismic performance of the PreWEC system. The relative vertical displacement imposed on the O-connector measured during the PreWEC tests confirmed that the O-connectors yield at both ends of the

403 wall. Because the inelastic strength of the O-connector in both the positive and negative loading directions is similar, the connectors impose equal and opposite forces on the wall panel and the axial load on the wall is not significantly affected by the number of connectors. This mechanism was confirmed by the similarities in the observed wall behaviour, damage, and measured neutral axis depth and compressive strains for SRW-B, PreWEC-A and PreWEC-B which had consistent dimensions and PT arrangement. The fact that the wall behaviour is independent of the number of O-connectors in the PreWEC system offers a significant advantage over other wall systems as supplemental damping can be added without compromising the wall design or performance.

410 As O-connectors were added in the PreWEC system, a significant increase in the hysteretic energy dissipation was

411 observed from SRW-B to PreWEC-A and PreWEC-B. This increase in energy dissipation would have substantial 412 benefits when considering the seismic performance, but did lead to an increase in residual drifts of the overall wall 413 system. Because the concrete compressive strains and neutral axis depth were the same for SRW-B, PreWEC-A1 and 414 PreWEC-B, the increase in measured residual drift between the SRW and PreWEC systems was primarily attributed to 415 the increased hysteresis area provided by the O-connectors. However, it should be noted that the residual drifts observed 
416 during the PreWEC tests are not an issue if the requirements for self-centring are considered appropriately during the

417 design process using procedures previously developed [21].

\section{$418 \quad 6$ CONCLUSIONS}

419 An experimental program consisting of five cyclic tests on four unbonded PT precast concrete wall systems was 420 conducted including two SRW (SRW-A and SRW-B) and two PreWEC systems (PreWEC-A and PreWEC-B). This experimental study systematically investigated the cyclic response of specimens with varying amounts of energy dissipation while keeping constant the initial post-tensioning, wall dimensions and confinement details for three walls and altering them significantly for the fourth wall. This allowed comparison of a variety of wall behaviours against a

424 previously developed simplified analysis method. For all tests the walls generally behaved as expected with only minor damage occurring at large lateral drifts. Based on the test observations and the measured results, the following conclusions were drawn:

- All of the four test walls were well designed with sufficient confinement and armouring details. Selection of an axial force ratio less than $10 \%$ led to an efficient design with a reduced risk of crushing in the wall toe. The use of the foam strip below the wall toe in SRW-B, PreWEC-A and PreWEC-B helped to further reduce the compressive strains and prevent the cover concrete spalling.

- Both SRW-A and SRW-B exhibited an approximate bi-linear response with a small amount of hysteresis equal to $3-5 \%$ EVD. The increase in EVD of SRW-B compared to SRW-A from 3\% to 5\% at $2 \%$ lateral drift demonstrated the influence of axial force ratio and inelastic strain in the wall toe on the hysteretic damping in the system.

- $\quad$ PreWEC-A and PreWEC-B showed increased strength and hysteresis due to the addition of the O-connectors. The EVD increased in proportion to the number of O-connectors with between 1.1-1.4\% EVD provided by each O-connector in the PreWEC walls tested.

- The PreWEC arrangement results in connector forces imposed on the wall panel that are equal and opposite. As a result of these balanced connector forces, the wall panel behaviour is independent of the number of $\mathrm{O}$ connectors and so supplemental damping can be added without compromising the wall design or performance.

- The increase in hysteresis area from an increase in O-connector number introduced higher residual drifts during the tests that need to be considered when designing the wall system to self-centre. 
- The simplified analytical method published by Aaleti and Sritharan [26] was able to capture both the global and local response parameters of all tests with sufficient accuracy. There were some small discrepancies in the prediction of the neutral axis depth at low lateral drifts and the deviation between the measured and predicted

- The initial stiffness of the walls was lower than the expected stiffness calculated using the gross section moment of inertia. An effective stiffness modifier was calculated based on the measured initial stiffness and the predicted initial stiffness. The proportion of the gross second moment of inertia required for the effective initial stiffness to be equal to the measured initial stiffness was between 0.61-0.64Ig for SRW specimens and 0.77-0.79Ig for PreWEC specimens.

\section{ACKNOWLEDGEMENTS}

453 Funding for this research was provided by the University of Auckland Engineering Faculty Research and Development 454 Fund. Support is also provided by National Science Foundation research award no. 1041650 through collaboration with 455 Iowa State University. Materials were donated by Stresscrete Northern Ltd, Contech, and Sika New Zealand. Assistance provided by Alex Shegay, James King, Dan Ripley, and Mark Byrami was much appreciated. Opinions, findings, conclusions, and recommendations in this paper are those of the authors, and do not necessarily represent those of the sponsors.

\section{REFERENCES}

[1] Kam WY, Pampanin S, Elwood K. Seismic performance of reinforced concrete buildings in the 22 February

461 Christchurch (Lyttelton) earthquake. Bulletin of the New Zealand Society for Earthquake Engineering. 2011;44:239-78.

462 [2] Sritharan S, Beyer K, Henry RS, Chai YH, Kowalsky M, Bull D. Understanding Poor Seismic Performance of

463 Concrete Walls and Design Implications. Earthquake Spectra. 2014;30:307-34.

464 [3] Priestley MJN, Sritharan SS, Conley JR, Pampanin S. Preliminary results and conclusions from the PRESSS fivestory precast concrete test building. PCI Journal. 1999;44:42-67.

468 [5] Stavridis A, Koutromanos I, Shing PB. Shake-table tests of a three-story reinforced concrete frame with masonry [4] Erkmen B, Schultz AE. Self-centering behavior of unbonded, post-tensioned precast concrete shear walls. Journal of Earthquake Engineering. 2009;13:1047-64.

[5] Stavridis A, Koutromanos I, Shing PB. Shake-table tests of a three-story reinforce

[6] Henry RS, Brooke NJ, Sritharan S, Ingham JM. Defining concrete compressive strain in unbonded post-tensioned walls. ACI Structural Journal. 2012;109:101-12.

[7] Holden T, Restrepo J, Mander JB. Seismic performance of precast reinforced and prestressed concrete walls. Journal of Structural Engineering. 2003;129:286-96.

[8] Restrepo JI, Rahman A. Seismic performance of self-centering structural walls incorporating energy dissipators. Journal of Structural Engineering. 2007;133:1560-70.

[9] Smith BJ, Kurama YC, McGinnis MJ. Design and measured behavior of a hybrid precast concrete wall specimen for seismic regions. Journal of Structural Engineering. 2011;137:1052-62.

[10] Smith BJ, Kurama YC. Seismic design guidelines for solid and perforated hybrid precast concrete shear walls. PCI Journal. 2014;59:43-59.

481 2013: Bridging Your Passion with Your Profession - Proceedings of the 2013 Structures Congress2013. p. 2626-37. 
[12] Marriott D. The Development of High-Performance Post-Tensioned Rocking Systems for the Seismic Design of Structures [PhD Thesis]. Christchurch: University of Canterbury; 2009.

[13] Kurama YC. Seismic design of unbonded post-tensioned precast concrete walls with supplemental viscous damping. ACI Structural Journal. 2000;97:648-58.

[14] Kurama YC. Simplified seismic design approach for friction-damped unbonded post-tensioned precast concrete walls. ACI Structural Journal. 2001;98:705-16.

[15] Kurama YC. Hybrid post-tensioned precast concrete walls for use in seismic regions. PCI Journal. 2002;47:36-59.

[16] Hamid NH, Mander JB. Lateral seismic performance of multipanel precast hollowcore walls. Journal of Structural Engineering. 2010;136:795-804.

[17] Hamid NH, Mander JB. Damage avoidance design for buildings. KSCE Journal of Civil Engineering. 2014;18:5418.

[18] Sritharan S, Aaleti S, Henry RS, Liu K-Y, Tsai K-C. Precast concrete wall with end columns (PreWEC) for earthquake resistant design. Earthquake Engineering \& Structural Dynamics. 2015.

[19] Henry RS, Aaleti S, Sritharan S, Ingham JM. Concept and finite-element modeling of new steel shear connectors for self-centering wall Systems. Journal of Engineering Mechanics. 2010;136:220-9.

[20] Henry RS, Aaleti S, Sritharan S, Ingham JM. Seismic analysis of a low-damage PREcast Wall with End Columns (PreWEC) including interaction with floor diaphragms. SESOC Journal. 2012;25.

[21] Twigden KM. Dynamic response of unbonded post-tensioned rocking walls [PhD Thesis]. Auckland: University of Auckland; 2015.

[22] New Zealand Standard. Concrete Structures Standard NZS 3101. Wellington, New Zealand2006.

[23] Sritharan S, Aaleti S, Thomas DJ. Seismic analysis and design of precast concrete jointed wall systems. ISU-ERIAmes Report ERI-07404. Ames, IA: Department of Civil, Construction and Environmental Engineering, Iowa State University; 2007.

[24] Henry RS. Self-centering precast concrete walls for buildings in regions with low to high seismicity [PhD Thesis]: University of Auckland; 2011.

[25] Mander JB, Priestley MJN, Park R. Theoretical stress-strain model for confined concrete. Journal of structural engineering New York, NY. 1988;114:1804-26.

[26] Aaleti S, Sritharan S. A simplified analysis method for characterizing unbonded post-tensioned precast wall systems. Engineering Structures. 2009;31:2966-75.

[27] Henry RS, Sritharan S, Ingham JM. Recentering requirements for the seismic deisgn of self-centering systems.

Proceedings of the Ninth Pacific Conference on Earthquake Engineering. Auckland, New Zealand2011.

[28] Oyarzo-Vera CA, McVerry GH, Ingham JM. Seismic zonation and default suite of ground-motion records for timehistory analysis in the North Island of New Zealand. Earthquake Spectra. 2012;28:667-88.

[29] Standards Association of Australia. Metallic materials : tensile testing at ambient temperature. 4th ed. ed. Sydney, NSW: Sydney, NSW : Standards Australia 2007.; 2007.

[30] Walsh KQ, Kurama YC. Behavior and design of anchorages for unbonded post-tensioning strands in seismic regions. 2008 Structures Congress - Structures Congress 2008: Crossing the Borders. Vancouver, BC2008.

[31] Twigden KM, Henry RS. Experimental response and design of O-connectors for rocking wall systems. Structures. 2015;3:261-71.

[32] ACI Innovation Task Group 5. Acceptance criteria for special unbonded post-tensioned precast structural walls based on validation testing and commentary : an ACI standard. Farmington Hills, Mich.: American Concrete Institute; 2008.

[33] Sritharan S, Aaleti S, Henry RS, Liu KY, Tsai KC. Introduction to PreWEC and key results of a proof of concept test. Pavia, Italy: IUSS Press; 2008.

[34] Aaleti S, Henry RS, Liu KY, Sritharan S, Tsai KC. Experimental investigation of a precast wall with end columns (PreWEC) system. Eleventh East Asia-Pacific Conference on Structural Engineering \& Construction (EASEC-11) "Building a Sustainable Environment". Taipei, Taiwan2008.

[35] Chopra AK. Dynamics of structures : Theory and applications to earthquake engineering. 3rd ed. Upper Saddle River, NJ: Prentice Hall; 2007. 